УДК 681.586

Ю. Ю. Бондаренко, к.т.н., доиент, e-mail: julybo110976@gmail.com

С. О. Філімонов, к.т.н., доиент, e-mail: s.filimonov@chdtu.edu.ua

А. О. Мисан, аспірант, e-mail: andreyka.misan@gmail.com

Д. С. Бачеріков, аспірант e-mail: abaka94@gmail.com

Черкаський державний технологічний університет б-р Шевченка, 460, м. Черкаси, 18000, Україна

\title{
ЗАЛЕЖНІСТЬ ЧАСТОТИ КОЛИВАНЬ ВІД ГЕОМЕТРИЧНИХ ПАРАМЕТРІВ П'ЄЗОКЕРАМІЧНОГО АКТУАТОРА ДЛЯ МАЛОГАБАРИТНИХ ЛІТАЛЬНИХ АПАРАТІВ
}

Робота знайшла своє застосування при конструюванні малогабаритних літальних апаратів, де як рушійну силу використовують п'єзокерамічні пластини. При конструюванні малогабаритних апаратів на основі п'єзокераміки є вкрай важливим вплив співвідношення довжини та ширини п'єзокерамічної пластини на ї̈ резонансну частоту. В результаті досліджень отримано математичні залежності для прогнозування частоти коливань залежно від геометричних розмірів п'єзоелектричної пластини. Адекватність отриманих чисельних розрахунків підтверджено експериментальними дослідженнями.

Ключові слова: малогабаритні літальні апарати, моделювання, n'єзокераміка, n'єзокерамічний актуатор.

Вступ. В статті приділено увагу особливостям конструювання малогабаритних літальних апаратів (МЛА), які здіймаються в повітря за допомогою крил, що відповідно грунтується на біонічному принципі - копіювання рухів літаючих живих об’єктів (птахів або комах) [1].

Як рушійну силу в малогабаритних літальних апаратах зазвичай використовують електромагнітні двигуни. На рисунку 1 зображено малогабаритний літальний апарат DelFly Explorer, в якому як рушійна сила використовується такий електродвигун [2].

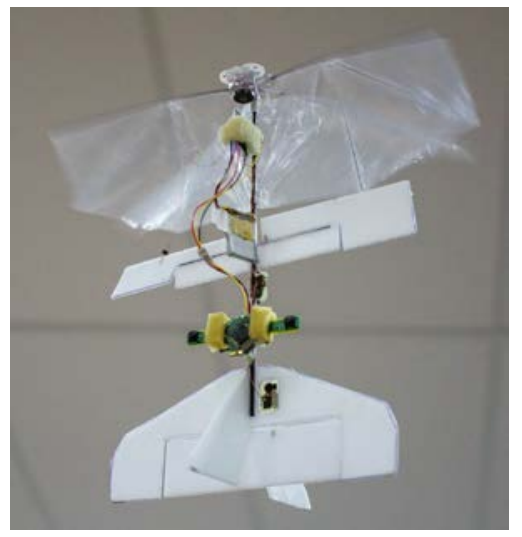

Рисунок 1 - DelFly Explorer
Зменшення конструкцій вимагає зменшення габаритів електромагнітних двигунів, що, в свою чергу, призводить до зменшення їх коефіцієнта корисної дії, а це неприпустимо. Таким чином, подальше зменшення конструкцій викликає зменшення габаритів електродвигуна, що призводить до зменшення вантажопідйомності [3].

В інших різновидах малогабаритних літальних апаратів як рушійну силу використовують п’єзоактуатори.

П'єзоактуатор - це п'єзомеханічний пристрій, що для приведення в дію механізмів, систем або управління ними використовує явище п'єзоелектричного ефекту.

Прикладом застосування п'єзоактуаторів як рушійної сили в малогабаритних літальних апаратах $\epsilon$ розробка вчених із Гарварда 3 проектом «RoboBees» на рисунку 2 [5]. Основним елементом RoboBees є п’єзоактуатор 1.

Використання п'єзоактуаторів як приводів має ряд переваг: швидкість спрацьовування, розвиток великих сил, відсутність магнітного поля, низьке споживання енергії, несхильність до зношування, можливість роботи в екстремальних умовах [4].

(C) Ю. Ю. Бондаренко, С. О. Філімонов, А. О. Мисан, Д. С. Бачеріков, 2019 DOI: 10.24025/2306-4412.2.2019.169493 
Таким чином, використання п’єзоактуаторів у малогабаритних літальних апаратах є більш раціональним.

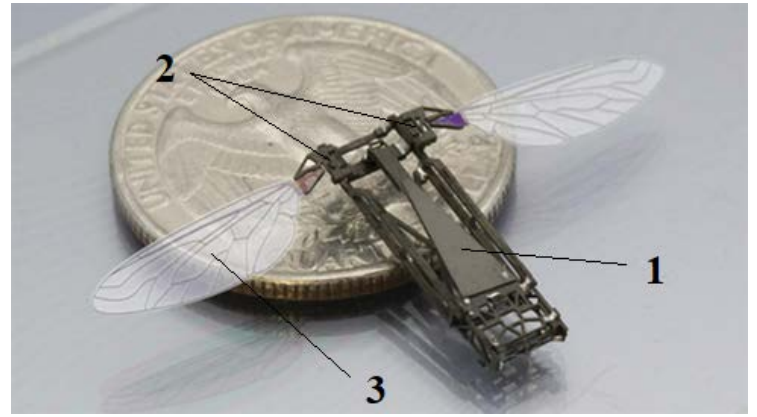

1 - п’єзокерамічний актуатор,

2 - редукторний механізм, 3 - крила

Рисунок 2 - RoboBees

Проте аналіз технічної літератури, наукових статей, а також патентів показав, що на сьогоднішній день невисвітленим є питання впливу геометричних розмірів на частотні характеристики п'єзоактуаторів. Таким чином, визначення впливу геометричних розмірів п'єзоактуатора на частотні характеристики $\epsilon$ важливою актуальною задачею, а іiі вирішення $\epsilon$ метою цієї роботи.

Опис об'скта і методу дослідження. Основною складовою п'єзокерамічного актуатора $\epsilon$ п'єзокерамічна пластина. На рисунку 3 зображено аксонометричну модель п’єзокерамічної пластини.

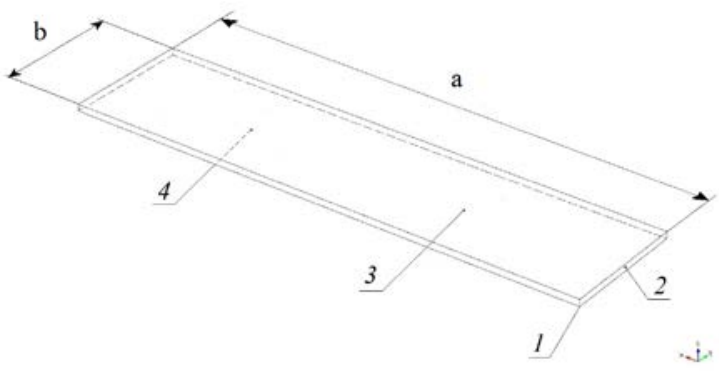

Рисунок 3 - Аксонометрична модель п’єзоелектричного актуатора

Враховуючи технічні особливості п'єзоелектричних актуаторів і всі складнощі, що виникають при їх виготовленні, оптимальним рішенням $\epsilon$ використання чисельних методів розрахунку, що реалізуються спеціальними САПР [6].

Для дослідження амплітуди коливань було проведено чисельне моделювання процесу роботи п'єзоелектричного актуатора в програмі COMSOL Multiphysics 5.2.
Всередині п'єзоелектричного елемента існує зв'язок між деформацією та електричним полем, який визначається матеріальним або конститутивним співвідношенням:

$$
\begin{array}{r}
T=C_{E} S-e^{T} E, \\
D=e S+\varepsilon_{S} E,
\end{array}
$$

де $S$ - деформація, $T$ - напруга, $E$ - електричне поле, $D$ - електричне зміщення поля.

Складові рівняння (1) $C_{E}$ і $e S \in$ комплексними величинами, що описують основні параметри матеріалу (відповідно жорсткість матеріалу, коефіцієнт електромеханічного зв'язку та діелектричну проникність). Ці величини $є$ тензорами 4-го, 3-го і 2-го рангу відповідно, але, оскільки тензори симетричні за фізичними причинами, вони можуть бути представлені у вигляді матриць у скороченому записі, що зазвичай $\epsilon$ більш зручним [7].

Використовувалися Лагранжові кінцеві елементи 3 елементарними базисними функціями другого порядку - Lagrange-Quadratic.

Аналіз п’єзокерамічного актуатора здійснювався в режимі Frequency response. Розрахункова сітка кінцевих елементів у пункті «Mesh» вибиралася ортогональною Normal. Сітка була побудована тетрагональним розбиттям, а досліджувані тривимірні моделі були представлені сукупністю з більш ніж тисячі елементів кожна. Як розв'язувач використовувався Direct, в якому був обраний чисельний метод SPOOLES для вирішення систем лінійних рівнянь 3 розрідженими матрицями.

Для визначення впливу геометричних розмірів на частоту п'єзоелектричного актуатора (рисунок 3) було проведено моделювання. Товщина п'єзопластини залишалася незмінною протягом усього циклу досліджень та становила 0,5 мм. Інші геометричні розміри п'єзокерамічної пластини були представлені коефіцієнтом $K=b / a$ в безрозмірній величині (відношення ширини основи $b$ до довжини $a$ ).

На першому етапі моделювання коефіцієнт $K$ змінювався від 0,27 до 0,44 з кроком 0,1 , при цьому ширина $b$ лишалася незмінною ( $b=5$ мм), а змінювалась тільки довжина $a$.

На другому етапі моделювання було досліджено вплив геометричних розмірів ширини $b$ на частоту коливань п'єзокерамічної пластини при постійній довжині $a(a=40$ мм), коефіцієнт $K$ змінювався аналогічно 3 першим етапом.

(C) Ю. Ю. Бондаренко, С. О. Філімонов, А. О. Мисан, Д. С. Бачеріков, 2019 DOI: 10.24025/2306-4412.2.2019.169493 
При моделюванні п’єзоелектричного актуатора були прийняті такі граничні умови: п’єзокерамічна пластина 1 по ширині площини 2 має тип граничних умов Fixed, електрична напруга (Electric potential) 100 В прикладена до електрода 5, а земля (Ground) - до електрода 4 на протилежній стороні (рисунок 3).

Для перевірки адекватності моделювання проводився експеримент з обраним актуатором, довжина якого становила 40 мм, ширина - 5 мм, а товщина - 0,5 мм.

Методика проведення експериментів полягала в наступному. П'єзоелектрична пластина 1 жорстко закріплювалася на основі 3 (рисунок 4).

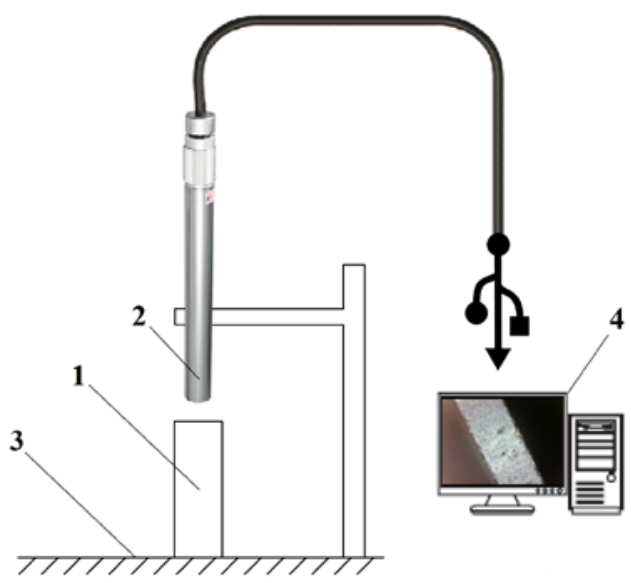

1 - п’єзоелектрична пластина, 2 - USB мікроскоп, 3 - основа, 4 - комп'ютер

Рисунок 4 - Схематичне представлення експериментальної установки для визначення коливань п'єзоелектричної пластини

При подачі змінної електричної напруги на електроди п'єзоелектричної пластини 1 в останній виникали механічні коливання, які фіксувалися USB мікроскопом 2. За значенням максимальної амплітуди коливань визначали частоту резонансу.

Опис результатів. Деякі результати чисельного моделювання п’єзоелектричного актуатора в процесі зміни довжини його п’єзоелектричної пластини при іiі постійній ширині зображено на рисунку 5. 3 рисунка 5 наочно видно динаміку зміни частоти та амплітуди коливань п'єзокерамічного актуатора залежно від зміни геометричних розмірів застосованої в ньому п'єзоелектричної пластини.

Отримані результати чисельного моделювання представлено графічно у вигляді залежності частоти коливань $f$ від коефіцієнта $K=b / a$ актуатора $\mathrm{i}$ зображено на рисунку 6 .
Eigenfrequency $=515.53$ Surface: Totat displacement $(\mu \mathrm{m})$
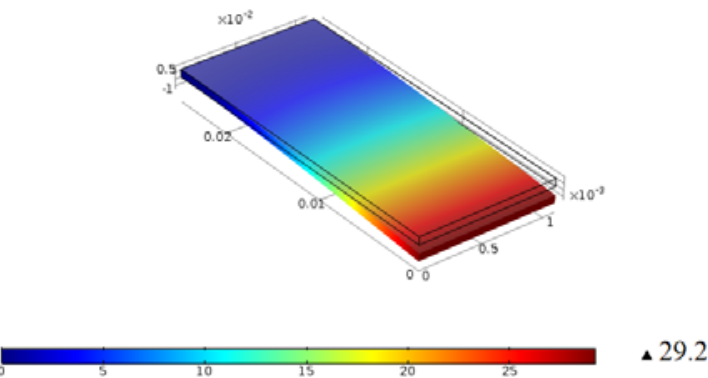

a)

Eigenfrequency $=196.82$ Surface: Total displacement $(\mu \mathrm{m})$

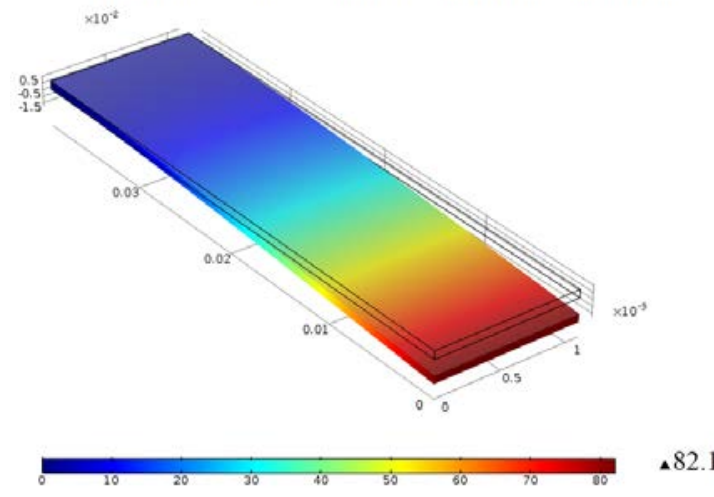

б)

a) $K=0,44$; б) $K=0,27$

Рисунок 5 - Результати моделювання п'єзоелектричного актуатора

3 різними значеннями коефіціснта $\boldsymbol{K}$ при постійній ширині п'єзоелектричної пластини

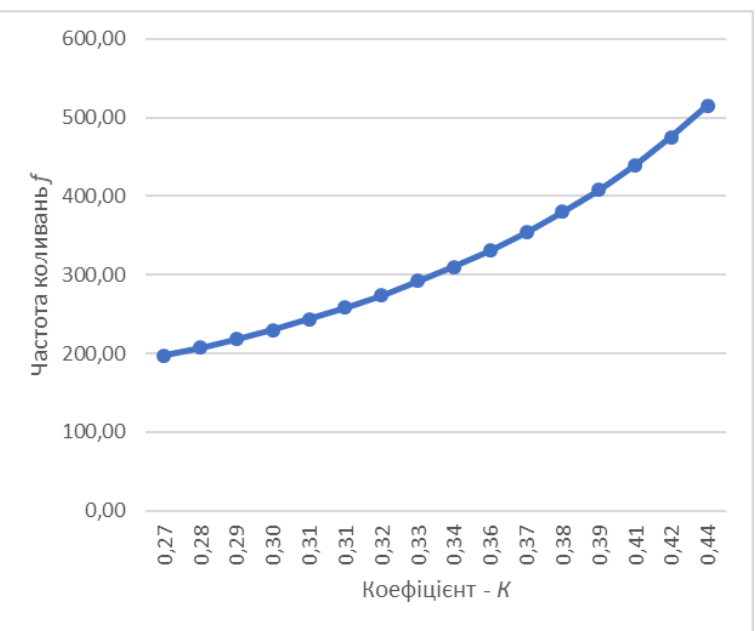

Рисунок 6 - Графік залежності частоти коливань $\boldsymbol{f}$ п'єзоелектричного актуатора при постійній ширині та 3 різними значеннями коефіціснта $\boldsymbol{K}$

(C) Ю. Ю. Бондаренко, С. О. Філімонов, А. О. Мисан, Д. С. Бачеріков, 2019 DOI: $10.24025 / 2306-4412.2 .2019 .169493$ 
3 рисунка 6 видно, що максимальна частота коливань 515 Гц п'єзоелектричного актуатора відповідає коефіцієнту $K=0,44$, що еквівалентно довжині $a=40 \mathrm{Mм}$.

Отримана в результаті чисельного моделювання графічна залежність для амплітуди коливань актуатора була апроксимована за допомогою квадратичної функції

$$
f=a+b x+c x^{2},
$$

де $f$ - частота коливань актуатора; $x$ - коефіцієнт $K ; a, b, c$ - коефіцієнти рівняння (відповідно $a=34,191882, b=-267,62638, c=3101,041)$.

Наступним кроком визначалася частота коливань $f$ при зміні ширини $b \quad$ п'єзоелектричної пластини при постійному значенні довжини $a=40$ мм. Ширина $b$ змінювалася в межах від 5 до 20 мм 3 кроком 1 мм. Зменшення ширини на величину, меншу ніж 5 мм, призводить до великих механічних напруг у п’єзоелектричній пластині, що може спричинити її руйнування. Деякі з результатів чисельного моделювання зображено на рисунку 7.

$$
\text { Eigenfrequency }=191.63 \text { Surface: Total displacement }(\mu \mathrm{m}){ }^{\circ}
$$
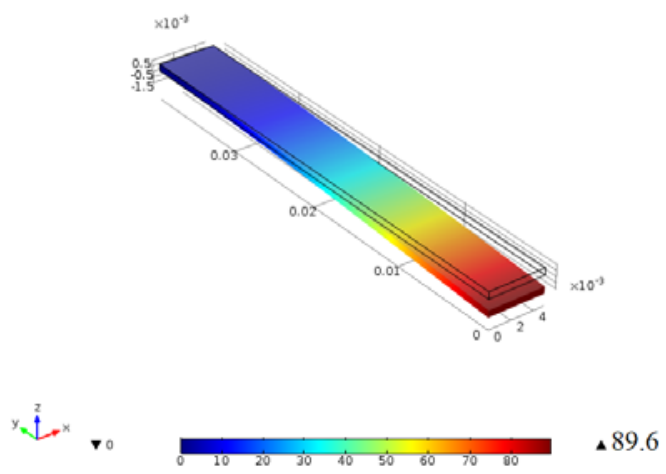

a)

Eigenfrequency $=203.09$ Surface: Total displacement $(\mu \mathrm{m})$

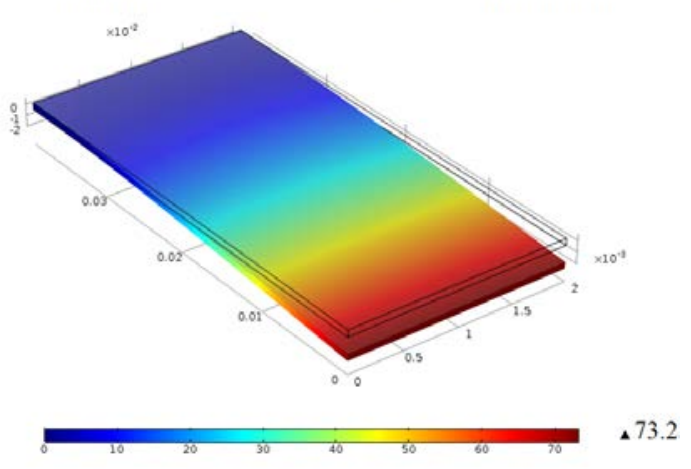

б)

a) $K=0,125$; б) $K=0,5$

Рисунок 7 - Результати моделювання п’сзоелектричного актуатора при постійній довжині $\boldsymbol{a}$ з різними коефіціснтами $K$
На основі результатів чисельного моделювання побудований графік залежності частоти коливань $f$ п'єзоелектричного актуатора 3 різними значеннями коефіцієнта $K$ при постійній довжині, який зображено на рисунку 8.

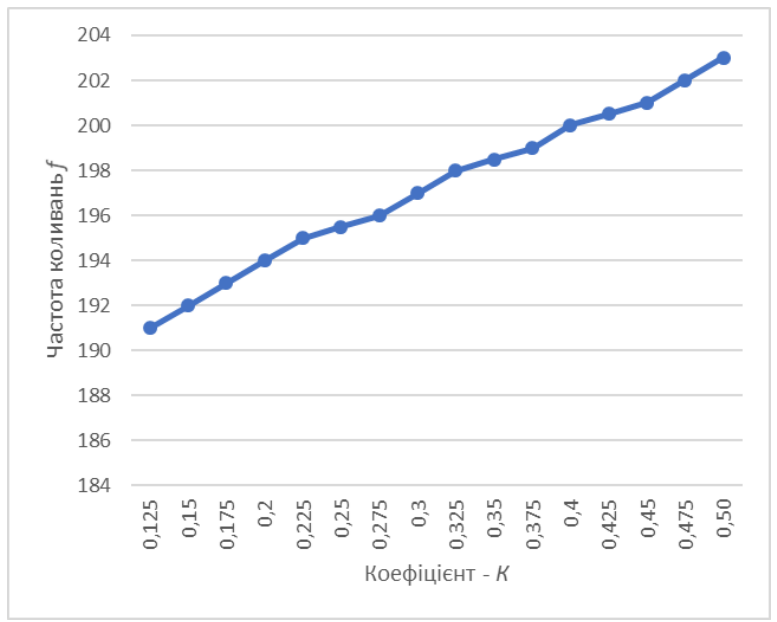

Рисунок 8 - Графік залежності частоти коливань $\boldsymbol{f}$ п'єзоелектричного актуатора при постійній довжині $\boldsymbol{a}$ з різними значеннями коефіціснта $K$

Таким чином, було встановлено, що за умови фіксації незмінною довжини актуатора та при зміні лише його ширини матиме місце лінійне зростання частоти коливань на проміжку $K$ від 0,125 до 0,5. Максимальна частота коливань у цьому випадку дорівнюватиме 203 Гц при $K=0,5$, тобто відповідатиме ширині пластини 20 мм, а мінімальна частота коливань становитиме 191 Гц при $K=0,125$, що відповідно еквівалентно ширині 5 мм.

Отриману в результаті чисельного моделювання залежність для частоти коливань було апроксимовано за допомогою лінійної функції

$$
f=a+b x,
$$

де $f$ - частота коливань актуатора, $x$ - коефіцієнт $K, a=187,19737, b=31,819549$ - коефіцієнти.

Для підтвердження результатів моделювання було проведено фізичний експеримент зі зразком п'єзоелектричної пластини. На рисунку 9 зображено стенд для експериментального дослідження п'єзокерамічних актуаторів. Результат моделювання було зіставлено з результатами фізичних експериментів на дослідних зразках. 


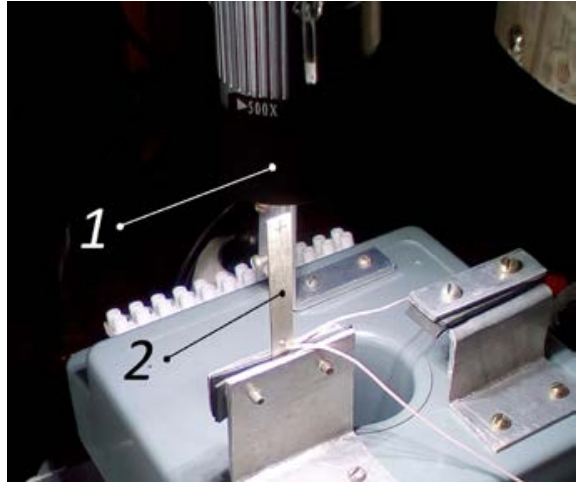

1 - USB мікроскоп; 2 - п’єзоелектрична пластина

Рисунок 9 - Експериментальна установка для визначення частоти коливань п'сзоактуатора

На рисунку 10 зображено візуалізацію коливань торця п'єзокерамічних пластин, отриману за допомогою мікроскопа.

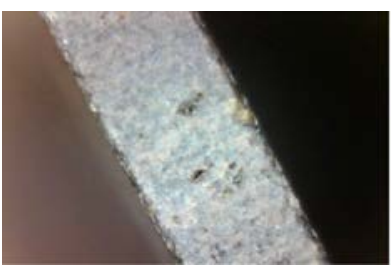

a)

a) в стані спокою;

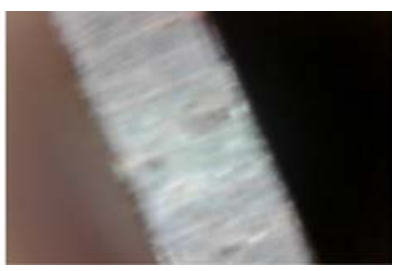

б) б) при подачі напруги 100 В з частотою 146 Гц

Рисунок 10 - Експериментальні результати візуалізації коливань вільної сторони п’єзоактуатора під мікроскопом, збільшення у 250 разів

Висновки. Таким чином, основні результати досліджень можна сформулювати наступним чином: шляхом чисельного моделювання було визначено залежності впливу геометричних параметрів п'єзоелектричних пластин на частоту коливань п'єзоактуаторів на їх основі. Отримані дані можна використовувати при проектуванні малогабаритних літальних апаратів чи в будь-яких інших пристроях, де як рушійна сила використовуються п’єзокерамічні актуатори подібної форми. Отримані математичні залежності допоможуть спрогнозувати зміну частоти коливань п’єзоактуаторів залежно від геометричних розмірів їх п’єзоелектричних пластин.

\section{Список літератури}

[1] Ю. Ю. Бондаренко, С. О. Филимонов, и А. А. Мисан, "Влияние геометрических параметров на амплитуду колебаний пье- зоэлектрического актуатора малогабаритных летательных аппаратов", Вісник Черкаського державного технологічного університету, № 2, с. 70-75, 2018 (Технічні науки).

[2] DelFly Explorer. [Online]. Available: http://www.delfly.nl/explorer.html

[3] А. Б. Смирнов, Мехатроника и робототехника. Системы микроперемещений с пьезоэлектрическими приводами. СанктПетербург: СПбГПУ, 2003.

[4] А. Е. Панич, и С. Н. Жуков, "Пьезоэлектрические актуаторы" (т. 4), в Пьезоэлектрическое приборостроение. Ростовна-Дону: ЦВВР, 2008.

[5] Wyss Institute. [Online]. Available: https://wyss.harvard.edu/technology/autono mous-flying-microrobots-robobees/

[6] В. И. Егоров, Применение ЭВМ для решения задач теплопроводности. СанктПетербург: СПб ГУ ИТМО, 2006.

[7] L. Spicci, and M. Cati, "Thermal analysis of a piezo-disk ultrasound probe", in Comsol Conference [in Paris], 2012.

[8] В. М. Лохин, "Тенденции развития беспилотных летательных аппаратов мини и микро классов", Нано- и микросистемная техника, № 2, 2005.

[9] V. Sharapov, Piezoceramic sensors. New York: Springer Verlag, 2011.

[10] С. Н. Жуков, Пьезоэлектрическая керамика: принципь и применение. Минск: ООО ФУАуинформ, 2003.

\section{References}

[1] Yu. Yu. Bondarenko, S. A. Filimonov, and A. A. Misan, "Influence of geometric parameters on the amplitude of oscillations of a piezoelectric actuator of small-sized flying vehicles", Visnyk Cherkaskogo derzhavnogo tekhnologichnogo universytetu, no. 2, pp. 70-75, 2018 [in Russian].

[2] DelFly Explorer. [Online]. Available: http://www.delfly.nl/explorer.html

[3] A. B. Smirnov, Mechatronics and robotics. Systems of micro-displacements with piezoelectric drives. St.Petersburg: SPbSPU, 2003 [in Russian].

[4] A. E. Panich, and S. N. Zhukov, "Piezoelectric actuators" (vol. 4), in Piezoelectric instrument making. Rostov-on-Don: CVUR, 2008 [in Russian]. 
[5] Wyss Institute. [Online]. Available: https://wyss.harvard.edu/technology/autono mous-flying-microrobots-robobees/

[6] V. I. Egorov, Application of a computer for solving problems of heat conduction. St. Petersburg: SPb GU ITMO, 2006 [in Russian].

[7] L. Spicci, and M. Cati, "Thermal analysis of a piezo-disk ultrasound probe", in Comsol Conference [in Paris], 2012.
[8] V. M. Lokhin, "Trends in the development of pilotless flying vehicles of mini and micro classes", Nano- i mikrosistemnaya tehnika, no. 2, 2005 [in Russian].

[9] V. Sharapov, Piezoceramic sensors. New York: Springer Verlag, 2011.

[10] S. N. Zhukov, Piezoelectric ceramics: principles and applications. Minsk: OOO FUAuinform, 2003 [in Russian].

Yu. Yu. Bondarenko, Ph. D., associate professor, e-mail: julybo110976@gmail.com

S. A. Filimonov, Ph. D., associate professor, e-mail: s.filimonov@chdtu.edu.ua

A. A. Misan, graduate student, e-mail: andreyka.misan@gmail.com

D. S. Bachirikov, graduate student, e-mail: abaka94@gmail.com

Cherkasy State Technological University

Shevchenko blvd, 460, Cherkasy,18006, Ukraine

\section{DEPENDENCE OF OSCILLATION FREQUENCY ON GEOMETRICAL PARAMETERS OF PIEZOCERAMIC ACTUATOR FOR SMALL-SIZED AIRCRAFT}

In the article the attention is paid to the peculiarities of the construction of small-sized aircraft flying into the air with the help of wings based on the bionic principle - copying movements birds or insects. Micro devices of such size and type have a wide range of applications and a number of tasks set before them, such as: pollination of crops, search and rescue operations, observation, as well as monitoring of weather, climate and environment with high resolution. The work has found its application in the design of small-sized aircraft, where piezoceramic plates are used as a driving force. The piezoceramics becomes much more relevant than that of an electric motor, since with the reduced design of a small-sized flying machine built on the basis of an electric motor, it will have to reduce the electromagnetic engine itself, that will lead to a loss in the efficiency factor of the engine and the aircraft in general. The piezoceramic engine is capable of converting electric energy into a mechanical one with a very high operating coefficient, which in some cases amounts to more than ninety percents. In addition, the use of piezoactuators has a number of advantages: operating speed, the development of large forces, the absence of a magnetic field, low energy consumption, no tendency to wear, the ability to work in extreme conditions. When constructing small-sized devices based on piezoceramics, the ratio of the length and width of the piezoceramic plate to its resonant frequency is extremely important. As a result of the research, mathematical dependences have been obtained for predicting the oscillation frequency, depending on geometric dimensions of the piezoelectric plate. The adequacy of the obtained numerical calculations is confirmed by experimental studies.

Keywords: small-sized planes, modeling, piezoceramics, piezoceramic actuator.

Стаття надійшла 05.06.2019

Прийнято 22.07.2019

(C) Ю. Ю. Бондаренко, С. О. Філімонов, А. О. Мисан, Д. С. Бачеріков, 2019 DOI: $10.24025 / 2306-4412.2 .2019 .169493$ 